\title{
Anomalous origin of the right coronary artery with aortopulmonary window: functional and surgical considerations
}

\author{
S V LUISI, M H ASHRAF, G GULA, R RADLEY-SMITH, AND M YACOUB \\ From Harefield Hospital, Harefield, Middlesex
}

ABSTRACT A rare case of anomalous origin of the right coronary artery from the pulmonar artery associated with a large aortopulmonary window in a 4-month-old boy is reported. The right coronary artery is exposed to systemic pressure and carries fairly well-oxygenated blood to the myocardium. Angiographic diagnosis could be difficult because of the simultaneous filling of both great arteries which obscures the origin of the anomalous vessel. Closure of the aortopulmonary window alone could result in acute myocardial ischaemia. A plastic procedur $\vec{B}$ for correction of this association of defects, which should allow normal growth, is described.

Anomalous origin of the right coronary artery from the pulmonary trunk is a rare congenital abnormality. ${ }^{12}$ Although usually discovered as an incidental finding at angiography, operation, or necropsy, ${ }^{3-5}$ it may produce myocardial ischaemia or sudden death. ${ }^{6}$ The association of this abnormality with other cardiac defects can affect their prognosis and management.

Our purpose in this paper is to report a patient with anomalous origin of the right coronary artery associated with an aortopulmonary window. The pathological findings, as well as the physiological effects, the clinical importance, and the method of correction of this combination are discussed.

\section{Case report}

A 4-month-old boy was referred to Harefield Hospital with a five-week history of congestive cardiac failure. On examination, he was a small, thin, acyanotic baby with talipes equinovarus. $\mathrm{He}$ had a respiratory rate of 80 per minute with marked intercostal recession and sternal bulging. His pulse rate was 140 per minute. There was a systolic thrill at the left sternal edge in the third intercostal space and a grade $3 / 4$ ejection systolic murmur at the left upper sternal border. His liver was enlarged. Electrocardiogram showed sinus rhythm with a mean frontal QRS vector of $+70^{\circ}$

Address for reprint requests: Mr MH Yacoub, Harefield Hospital, Harefield, Middlesex. and biventricular hypertrophy. Chest radiograph showed a dilated main pulmonary artery, a prom nent left ventricle, and plethoric lung fields. $O$ S cardiac catheterisation there was a large left-to right shunt at arterial level with systemic pressuro in the pulmonary artery (table). Aortography

Table Preoperative cardiac catheterisation data

\begin{tabular}{|c|c|c|c|}
\hline \multirow[b]{2}{*}{ Left ventricle } & Pressure $(\mathrm{mmHg})$ & \multicolumn{2}{|c|}{$\mathrm{O}_{2}$ saturation $(\%$} \\
\hline & $82 / 10$ & 96 & \\
\hline Aorta & $85 / 40$ & 91 & \\
\hline Right ventricle & $75 / 2$ & - & \\
\hline Main pulmonary artery & $75 / 40$ & 93 & \\
\hline Right pulmonary artery & $70 / 35$ & 96 & \\
\hline Superior vena cava & 3 & 61 & \\
\hline Mid right atrium & 3 & 71 & \\
\hline Inferior vena cava & 3 & 67 & \\
\hline Left atrium & 5 & 95 & \\
\hline
\end{tabular}

showed a large aortopulmonary window. The origins of the coronary arteries were not seen. A operation an aortopulmonary window $(2 \mathrm{~cm}$ i diameter) was found just above the pulmonar valve. There was an anomalous origin of the righ coronary artery from the pulmonary trunk wit the ostium situated $0.5 \mathrm{~cm}$ anterior to the margin of the window. The vessel was of normal size ang located with its branches in a normal positiola The left coronary artery was normal. The opersक tion was performed with the aid of cardiopup monary bypass, deep hypothermia and myocardia protection by cold cardioplegia. The border of the 
window was divided and a flap of the pulmonary wall, including the ostium of the right coronary artery, was anastomosed to the aorta to close the aortic defect (figure). The pulmonary artery was repaired by direct suture.

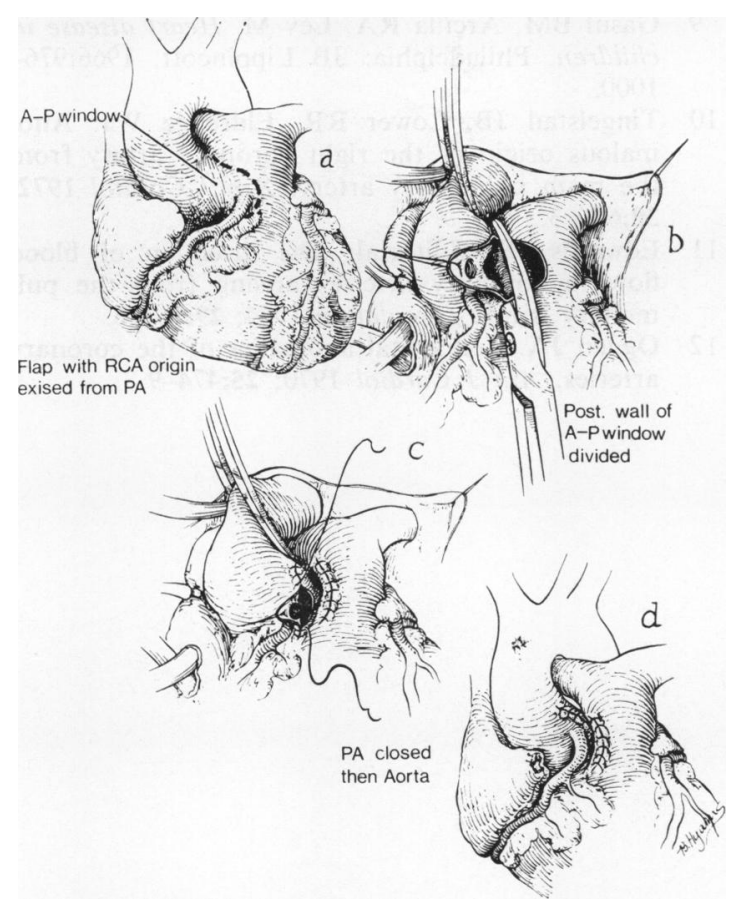

Figure Diagram illustrating the method of transposing the anomalous right coronary artery from the pulmonary trunk to the aorta and closure of the aortopulmonary window. $(R C A=$ right coronary artery, $P A=$ pulmonary artery, $A P=$ aortopulmonary window).

After correction, the left ventricular pressure was $78 / 4 \mathrm{mmHg}$ and the right ventricular pressure $32 / 4 \mathrm{mmHg}$. The postoperative course was uneventful and the patient was discharged 10 days later. A two-year follow-up examination showed the child to be asymptomatic with no abnormal clinical findings. The chest radiograph and electrocardiogram have reverted to normal.

\section{Discussion}

The association of anomalous origin of the right coronary artery from the pulmonary trunk with aortopulmonary window is very rare. To our knowledge only two cases have been reported, apart from the patient described in this paper. ${ }^{78}$
One patient had, in addition, a ventricular septal defect and malposition of the great arteries. ${ }^{8}$ The anomalous vessel originates from the pulmonary artery in close proximity to the aortopulmonary window and follows its normal course in the right atrioventricular groove. Both coronary arteries are of normal calibre with no significant collateral vessels. Because of the presence of a large aortopulmonary window, the anomalous right coronary artery is exposed to systemic pressure and carries fairly well-oxygenated blood from the pulmonary trunk to the myocardium.

This situation is quite different from that seen in patients in whom the right coronary artery anomaly is the sole lesion where the vessel is very thin-walled and resembles a vein, although histologically it has the basic structure of an artery. The left coronary artery, in these patients, is dilated and tortuous and, in most cases, gives several large intra-arterial anastomotic channels to the right coronary artery..$^{3} 910$ The presence of a left-to-right shunt through a low resistance coronary artery system ${ }^{11}$ can cause a pulmonary steal from the myocardium, ${ }^{6}$ although it rarely produces clinical and electrocardiographic features of myocardial ischaemia. ${ }^{12}$

The clinical picture of patients with an additional aortopulmonary window is dominated by the signs of the left-to-right shunt through the window. In our case the origin of the right coronary artery was not seen after an aortic root injection, presumably because of the almost simultaneous opacification of both great vessels which obscured the anomalous vessel. ${ }^{8}$ Prognosis depends mainly on the degree of the left-to-right shunt.and pulmonary vascular resistance. Early diagnosis and surgical correction are essential to prevent the onset of intractable congestive heart failure and irreversible pulmonary vascular disease. The anomalous right coronary artery must be identified at operation, because closure of the window can cause acute ischaemic changes or myocardial infarction from a sudden fall in the right coronary pressure in the absence of well-developed anastomotic channels from the left coronary artery. Furthermore, late complications from myocardial ischaemia may occur. The anomaly can be corrected by a plastic procedure which should allow normal growth.

\section{References}

1 Soloff LA. Anomalous coronary arteries arising from the pulmonary artery. Am Heart J 1942; 24:118-27. 
2 Vlodaver Z, Neufeld, HN, Edwards JE. Coronary arterial variations in the normal heart and in congenital heart disease. New York: Academic Press, 1975:94-7.

3 Cronk ES, Sinclair JG, Rigdon RH. An anomalous coronary artery arising from the pulmonary artery. Am Heart J 1951; 42:906-11.

4 Ranniger K, Thilenius OG, Cassels DE. Angiographic diagnosis of an anomalous right coronary artery arising from the pulmonary artery. Radiology 1967; 88:29-31.

5 Rowe GG, Young WP. Anomalous origin of the coronary arteries with special reference to surgical treatment. J Thorac Cardiovasc Surg 1960; 39:777-80.

6 Wald S, Stonecipher K, Baldwin BJ, Nutter DO. Anomalous origin of the right coronary artery from the pulmonary artery. Am J Cardiol 1971; 27:677-81.
7 Blieden LC, Moller JH. Aortico-pulmonary septaks defect-an experience with 17 patients. Br Hearto J 1974; 36:630-5.

8 Burroughs JT, Schumutzer KJ Linder F, Neuhans G. Anomalous origin of the right coronary arteryo with aortico-pulmonary window and ventricular septal defect. J Cardiovasc Surg 1962; 3:142-8. क

9 Gasul BM, Arcilla RA, Lev M. Heart disease in 5 children. Philadelphia: JB Lippincott, 1966:9761000.

10 Tingelstad JB, Lower RR, Eldredge WJ. Ano $\stackrel{\circ}{2}$ malous origin of the right coronary artery from the main pulmonary artery. Am J Cardiol 1972 30:670-3.

11 Edwards JE. Editorial: The direction of blood flow in coronary arteries arising from the pul| monary trunk. Circulation 1964; 29:163-6.

12 Ogden JA. Congenital anomalies of the coronary? arteries. Am J Cardiol 1970; 25:474-9. 